\begin{tabular}{|c|c|}
\hline \multirow{3}{*}{ 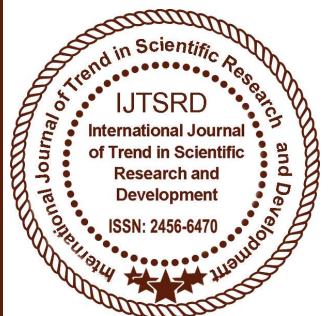 } & $\begin{array}{l}\text { International Journal of Trend in Scientific } \\
\text { Research and Development (IJTSRD) }\end{array}$ \\
\hline & International Open Access Journal \\
\hline & ISSN No: 2456 - 6470 | www.ijtsrd.com | Volume - 2 | Issue - 2 \\
\hline
\end{tabular}

\title{
Fertility Response Following Induction of Lactation in Infertile Dairy Cows
}

\author{
K. Kumar \\ S. N. Shukla \\ S. K. Singh \\ Post Graduate Student, CVSc \& \\ Associate Professor, Vetey. \\ AH, NDVSU Jabalpur M.P., India \\ Gynaecology and obstetrics, CVSc \\ \& AH, NDVSU Jabalpur, M.P.

\begin{abstract}
Post Graduate Student, CVSc \&
\end{abstract} \\ AH, NDVSU Jabalpur, M.P., India \\ P. Inwati \\ T.A., Vetey. Gynaecology and Obstetrics, \\ CVSc \& AH, NDVSU Jabalpur M.P.

\section{S. Bhandekar} \\ T.A., Vetey. Gynaecology and Obstetrics, \\ CVSc \& AH, NDVSU Jabalpur M.P.
}

\section{ABSTRACT}

The fertility response following induction protocol in infertile dry cows was assessed in terms of the induction of oestrus in anoestrus cows and conception in repeat breeder's cows in the study. There were four anoestrous and two repeat breeder cows in G-1 out of them two anoestrus became cyclic, one repeater animal conceived after treatment protocol. Where as in G-2, three anoestrus and three repeat breeder animals given induction protocol where two anoestrous cows became cyclic and two repeaters conceived. The analysis of data revealed higher fertility response in G-2 as compared to G-1 (66.67 Vs. $50 \%$, respectively) with the higher conception rate (50 Vs. $33.33 \%$, respectively). It indicates better fertility response in G-2 as compared to G-1.

Keyword: Fertility, Infertile, cow, repeater

\section{INTRODUCTION}

India ranks first among the world's milk producing countries since 1998 and has the largest bovine population in the World. Livestock sector is an integral part of Indian agriculture, contributing about $30 \%$ of total agrarian economy of country. Among farm animals, cattle and buffalo are the premier milk producing animals, contributing most of the total milk production in the country. Indian has more than 50 percent cattle population (199.9 million) contributing less milk production than buffalo. Madhya Pradesh rank first in cattle population $(10.27 \%, 151.17$ million indigenous and 39.73 million crossbred/exotic) in the country.In India stray cow menace is increasing day by day as cow slaughter and their use for meat purpose is not an option. Farmers do not want to keep the cows that become repeat breeders for longer period of time and cease giving milk and thus left stray on the roads.

These stray animals again pose many kind of risks to the people in the form of accidents, zoonosis etc. Therefore, Induced lactation of non-pregnant cows may be a management alternative to reduce culling and increase profits (Magliaro et al., 2004).

Now a days, it is possible to induce lactation in sub fertile dairy animals which otherwise will have to be culled. The later is also not suitable preposition in India. So, artificial induction of lactation reduces the cost of maintaining barren non lactating animals in the herd. Protocols for the induction of lactation in nonlactating and non-pregnant dairy cows have focused on the practical uses of these procedures on farms (Fulkerson, 1979). 
Early attempts to induce lactation using long-term treatments (120-180 days injection regimens of oestrogen and progesterone) resulted in low milk yields and low rates of success.

To date the available most of the protocols have been used with the pure forms of hormones or chemicals which are very costly and preparations are not available easily especially in ready to use form thus putting question mark to use at field level. Therefore, as an alternate way to overcome such problems, the injectable depot form of oestrogen and progesterone which are easily available in the market and easy to use may be tried for induction of lactation in cows.

The proposed work was aimed with the hypothesis to induce lactation in such animals on one hand and treating infertility by the means of priming the reproductive tract with oestrogen and progesterone on the other hand. The recommendation of present study may support rehabilitating stray cows to reduce stray cow menace. The proposed protocols are comparatively cost effective due to easy and abundant availability of hormonal preparations. Keeping the above facts in view, the present study was designed.

\section{Material and Methods}

The proposed work was carried out in animals of Livestock Farm Adhartal, Jabalpur, at farmer's door and Department of Veterinary Gynaecology and Obstetrics, College of Veterinary Science and Animal Husbandry, Nanaji Deshmukh Veterinary Science University Jabalpur (M.P). Infertile and non-lactating dairy cows were used for this study. Study was conducted on total 12 non-lactating parous, approximately 4-8 years old, non-pregnant cows having good body condition score (BCS) between 2-4 of 5 point scale, history of good milk production in the previous lactation (approx 10 litre/day) and infertility (anoestrus and repeat breeding) since last six months or more. The experiment was conducted in 12 selected cows, randomly divided into two groups each containing six animals $(n=6)$. Animals of group1 (G-1) treated with intramuscular injection of estradiolvalerate depot @ $0.10 \mathrm{mg} / \mathrm{kg}$ along with injection of hydroxy progesterone depot@0.25 $\mathrm{mg} / \mathrm{kg}$, OID for seven days. Intramuscular Injection of dexamethasone@0.050mg/kg, OID at 10,11, 12 and 13 day then hand milking started onwards. In group-2 (G-2) intramuscular injection of estradiolvalerate depot@0.10 mg/kg along with consecutive injection of hydroxy progesterone depot @ $0.25 \mathrm{mg} / \mathrm{kg}$ OID for seven days was given. After that Intramuscular injection of dexamethasone @ $0.050 \mathrm{mg} / \mathrm{kg}$ along with metoclopromide@0.10 mg/kg OID at 10,11,12 and 13 day. The data generated were analysed statistically using t-test assuming equal variance in Microsoft excel software 2007.

\section{Results and Discussion:}

Table 1: Individual fertility response in different groups following induction protocol

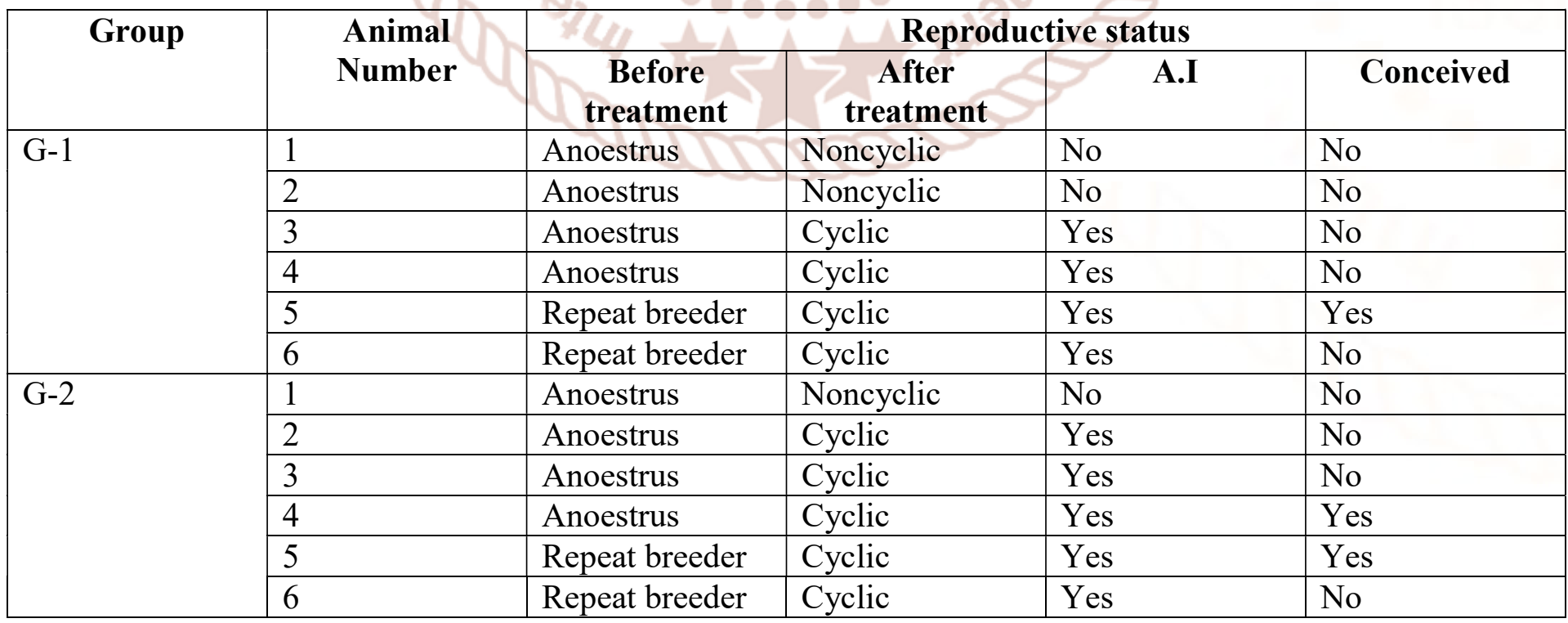


Two anoestrous animal out of four became cyclic following induction protocol using estrogen, progesterone and dexamethasone (G-1). Delous et al. (1978) reported that oestrous cycle activity was abnormal and showed regular oestrous cycle within two months of lactation after induction protocol. In most of the studies pure form of hormonal preparation used which are costly, not available in ready to use form and difficult to use at farm door.
Although better fertility in this study along with milk induction protocols may not be optimum as small sample size of experimental animals. However, this may be promising as hormonal preparation used in this study is abundant in availability, easy to use and store.

\section{Table 2: Conception rate following induction of lactation in infertile cows}

\begin{tabular}{|l|c|c|}
\hline Particular G & 1 G & $\mathbf{2}$ \\
\hline $\begin{array}{l}\text { Total number of } \\
\text { animals (N) }\end{array}$ & 6 & 6 \\
\hline $\begin{array}{l}\text { Animals responded } \\
\text { to treatment }\end{array}$ & $3(50.00 \%)$ & $4(66.66 \%)$ \\
\hline $\begin{array}{l}\text { Animals } \\
\text { inseminated }\end{array}$ & 3 & 4 \\
\hline Conception rate & $1(33.33 \%)$ & $2(50.00 \%)$ \\
\hline
\end{tabular}

\section{Conclusion}

The study can be concluded that induction of lactation can be achieved by short duration protocol using commercially available injectable oestrogen and progesterone depot with satisfactory milk recovery in infertile dry cows. Induction of lactation protocol using ready to use injectable hormonal preparations of oestrogen and progesterone in 1:2.5 ratio also induced 50-66.7 percent fertility response in infertile cows with conception up to 50 percent.

\section{References}

1. Ball, S., Polson, K., Emeny, J., Eyestone, W. and Akers, R.M. 2000. Induced lactation in prepubertal heifers.Journal of Dairy Science, 83(11): 2459-63.

2. Chakriyarat, S., Head, H.H., Thatcher, W.W., Neal, F.C. and Wilcox, C.J. 1978. Induction of lactation: Lactational, physiological and hormonal responses in the bovine. Journal of Dairy Science, 61: 1715.

3. Collier, R.J., Bauman, D.E. and Hays, R.L. 1975. Milk production and reproductive performance of cows hormonally induced into lactation. Journal of Dairy Science, 58: 1524.
4. Delouis, C., Djiane, J., Kann, G., Tergui, M. and Head, H.H. (1978).Induced lactation in cows and heifers by short-term treatment with steroid hormones.Annual Biological Animal Biochemistry and Biophysics, 18: 721.

5. Fulkerson, W.J. 1979. Hormonal control of lactation. Canadian Journal of Veterinary Science, 28: 183-87.

6. Kaskous, G.E. and Mielke, H. 1995.Investigations on the composition of milk after artificial induction of lactation in 12-19 months old heifer.Berliner-Und-Munchencer-TierarlicheWochenschrift, 108: 333-38.

7. Magliaro, A.L., Kensinger, R.S., Ford, S.A., Connor, M.L., Muller, L.D. and Graboski, R. (2004).

8. Induced lactation in non-pregnant cows, profitability and response to bovine somatotropin. Journal of Dairy Science, 87: 3290-3297.

9. Mohan, K., Shreedhar, N.B., Jaykumar, K. and Manafi, M. 2010. Comparison of milk estrogen and progesterone concentration in induced heifers and normally calved lactating cows.Asian Journal of Animal and Veterinary Advance, 5: 260-265.

10. Pangaonkar, G.R., Verma, H.K., Kumar, S., Jindal, R. and Sidhu, S.S. 2002. Artificial lactogenesis in bovines.Agricultural Research Journal,41: 266-283.

11. Suresh Babu, D., Reddy, Y., Naidu, K. and Reddy, K.K. 1996. Changes in udder and Teat measurements in artificially induced lactating crossbred cattle. Livestock Advisor, 21: 3-8. 